\title{
Evaluation of Quality of Life in Patients With Narcolepsy Treated With Sodium Oxybate: Use of the 36-Item Short-Form Health Survey in a Clinical Trial
}

Richard Bogan · Todd Swick • Mortimer Mamelak - Ruzica Kovacevic-Ristanovic •

Chinglin Lai · Jed Black · Kathleen F. Villa · Jacques Montplaisir

Received: July 19, 2016 / Published online: October 24, 2016

(C) The Author(s) 2016. This article is published with open access at Springerlink.com

\section{ABSTRACT}

Introduction: The present post hoc analysis was designed to evaluate health-related quality of life (HRQoL) using the 36-item Short Form

Enhanced content To view enhanced content for this article go to http://www.medengine.com/Redeem/ EC07F0602E6CF663.

R. Bogan $(\bowtie)$

Medical University of South Carolina School of

Medicine, Charleston, SC, USA

e-mail: RBogan@sleepmed.md

\section{T. Swick}

Neurology and Sleep Medicine Consultants of Houston, University of Texas-Houston School of Medicine, Houston, TX, USA

M. Mamelak

Department of Psychiatry, University of Toronto,

Toronto, ON, Canada

R. Kovacevic-Ristanovic

Department of Neurology, Sleep Disorders Center, ENH-Evanston Hospital, Evanston, IL, USA

C. Lai · J. Black · K. F. Villa

Jazz Pharmaceuticals, Palo Alto, CA, USA

J. Black

Stanford Center for Sleep Research and Medicine,

Stanford, CA, USA

J. Montplaisir

Department of Psychiatry, Université de Montréal, Montréal, QC, Canada
Health Status Survey (SF-36) during an 8-week trial of sodium oxybate (SXB).

Methods: SF-36 was assessed in a phase 3 placebo-controlled trial in patients with narcolepsy $(N=228)$ randomized to placebo or SXB in doses of 4.5, 6, or $9 \mathrm{~g}$ nightly for 8 weeks. Changes from baseline in SF-36 (last observation carried forward) were compared between SXB and placebo, and effect sizes (ES) were estimated.

Results: Baseline SF-36 values were lower than normative values for the US general population. After 8 weeks of treatment, mean ( \pm standard deviation) improvement from baseline on the Physical Component Summary (PCS) was significantly greater with SXB $9 \mathrm{~g} /$ night than placebo (6.3 \pm 9.1 vs. $1.5 \pm 6.2 ; p=0.005)$, with moderate ES; no significant difference was found between the SXB and placebo groups on the Mental Component Summary. SXB $9 \mathrm{~g} /$ night resulted in significantly $(p<0.05)$ greater improvements than placebo in Physical Functioning $(4.4 \pm 9.2$ vs. $1.0 \pm 8.0)$, General Health (GH; $3.1 \pm 7.0$ vs. $0.4 \pm 6.8$ ), and Social Functioning $(6.8 \pm 16.8$ vs. $1.1 \pm 9.6)$. All SXB doses resulted in significant improvement $(p<0.05)$ relative to placebo for Vitality, with 
moderate ES. No significant differences versus placebo were observed for Role-Physical, Role-Emotional, or Mental Health domains.

Conclusion: Treatment with SXB was associated with a dose-dependent improvement in HRQoL, with the 9-g nightly dose demonstrating a positive impact on PCS and individual SF-36 domains of Vitality, GH, and Physical and Social Functioning.

Trial registration: NCT00049803.

Funding: Jazz Pharmaceuticals.

Keywords: Narcolepsy; Sodium oxybate; Quality of life; SF-36

\section{INTRODUCTION}

Excessive daytime sleepiness (EDS) and cataplexy (intermittent partial or complete muscle paralysis) are the most frequently recognized symptoms of narcolepsy, with hallucinations upon falling asleep or awakening, sleep paralysis, and disrupted nighttime sleep completing the pentad of symptoms associated with this disease $[1,2]$. While onset of narcolepsy generally occurs in childhood or early adulthood $[3,4]$, it has consistently been reported that there can be a delay of 10-15 years between symptom onset and confirmed diagnosis, with the lack of recognition by physicians the primary reason for this delay [5]. This failure to recognize the signs and symptoms of narcolepsy not only contributes to reported misdiagnosis [6, 7], but also delays appropriate treatment, thereby prolonging the adverse psychosocial impact of the disease [5].

\section{Health-Related Quality of Life in Narcolepsy}

In addition to the disease-related physical impairment and the recognized economic burden of narcolepsy resulting from the direct costs of higher healthcare resource utilization and indirect costs associated with unemployment and lost productivity [8-10], there is a substantial humanistic burden. Patients with narcolepsy not only tend to have a greater prevalence of comorbidities and higher odds of mortality than those without narcolepsy [11-13], but health-related quality of life (HRQoL) has been shown to be reduced across countries and cultures [14-23]. In particular, studies using the 36-item Short Form Health Status Survey (SF-36) to assess HRQoL in patients with narcolepsy have reported lower scores in most SF-36 domains compared to the general population as well as to those experiencing obstructive sleep apnea, Parkinson's disease, and epilepsy [14-16, 18-24].

Because there is no cure for narcolepsy, treatment occurs over the lifetime of the patient, with EDS and cataplexy the main targets of most current therapies $[25,26]$. Sodium oxybate (SXB) is the sodium salt of gamma hydroxybutyrate, an endogenous metabolite of gamma-aminobutyric acid; SXB is approved for the treatment of cataplexy and EDS in narcolepsy [27]. Randomized controlled trials have demonstrated the efficacy of SXB for reducing EDS and the frequency of cataplexy attacks in patients with narcolepsy [28-30]. Improvements in functional outcomes, assessed using the Functional Outcomes of Sleep Questionnaire (FOSQ) [31], have also been suggested [32]. However, no studies to date have reported on the effects of SXB on HRQoL using a standard assessment measure such as the SF-36.

\section{Objective}

The purpose of this analysis is to provide data on the effect of SXB on HRQoL collected during an 8-week randomized controlled trial. 


\section{METHODS}

\section{Design and Patients}

This analysis of HRQoL in patients with narcolepsy treated with SXB is based on data obtained during an 8-week phase 3 randomized placebo-controlled trial. Details of the study design and methods were published previously [29]. Patients $\geq 16$ years of age with a diagnosis of narcolepsy with cataplexy, based on clinical history, an overnight polysomnogram, and multiple sleep latency test, were randomized to 8 weeks of treatment with placebo or with SXB in doses of $4.5,6$, or $9 \mathrm{~g}$, administered as two equally divided nightly doses; the second dose was taken $2.5-4 \mathrm{~h}$ after the first dose. For patients receiving 6 and 9-g doses of SXB, the doses were titrated in weekly 1.5 -g increments. The use of stable doses of stimulants for the treatment of EDS was allowed.

\section{Medical Outcomes Survey 36-Item Short Form}

To assess changes in HRQoL associated with treatment, the Medical Outcomes Survey SF-36 [33, 34] was administered during the study as an exploratory efficacy endpoint. The SF-36 is a widely used generic instrument for evaluating HRQoL, consisting of eight subscales evaluating specific health status domains and two summary scales, a Physical Component Summary (PCS) and a Mental Component Summary (MCS). The domain subscales include Physical Functioning (ability to perform physical activity); Role-Physical, which assesses the impact of physical function on daily roles (work, daily activities); Bodily Pain (presence of pain and its impact on limiting activities); General Health (GH; overall health status); Vitality (energy and tiredness); Social Functioning (ability to perform social activities); Role-Emotional (impact of emotional problems on participation in life activities such as work and other daily activities); and Mental Health (general mood, i.e., anxiety, depression). The PCS is derived from positively weighting the domains of Physical Functioning, Role-Physical, Bodily Pain, and $\mathrm{GH}$, while the MCS weights the domains of Vitality, Social Functioning, Role-Emotional, and Mental Health. Scores on the SF-36 range from 0 to 100, with higher scores indicating better health status. Normative values for the US population have been published [35], and a change of five points is generally accepted as the minimum clinically important difference (MCID) [36].

\section{Statistical Analyses}

The SF-36 was administered at baseline and at weeks 4 and 8 , with efficacy measured as change from baseline at the end of double-blind treatment (week 8) using a last-observation-carried-forward analysis on the intent-to-treat population. Scores were transformed to norm-based scoring using 1998 SF-36 US population norms [37].

Within-group change from baseline was evaluated using a paired $t$ test, and differences in the change from baseline between groups were evaluated using an analysis of variance model with adjustment for treatment and site. Pairwise comparisons versus placebo were performed if the overall $p$ was less than 0.05. Effect sizes (ES) versus placebo were estimated based on the difference between the mean change from baseline in the active treatment group and the mean change in the placebo group divided by the pooled standard deviation (SD) of the active and 
placebo treatment groups (Cohen's d); ES of 0.20 are generally considered small, 0.50 are moderate, and 0.80 are large [38].

Statistical analyses were performed using SAS version 9 software (SAS Institute, Inc., Cary, NC, USA).

\section{Compliance with Ethics Guidelines}

All procedures followed were in accordance with the ethical standards of the responsible committee on human experimentation (institutional and national) and with the Helsinki Declaration of 1964, as revised in 2013. Informed consent was obtained from all patients for inclusion in the study (ClinicalTrials.gov identifier NCT00049803).

\section{RESULTS}

\section{Demographics and Clinical Characteristics}

Demographic characteristics of the intent-to-treat population were similar across the study groups (Table 1). Overall, patients were predominantly female $(65.4 \%)$ and white $(86.0 \%)$, with a mean \pm SD age of $40.5 \pm 15.3$ years. The clinical characteristics of narcolepsy in these patients were also similar across groups, and showed that the population was characterized by moderate-to-severe disease. In particular, the mean Epworth Sleepiness Scale (ESS) score ranged from 17.3 to 18.2 across treatment groups (scores $\geq 10$ are considered to represent clinically important sleepiness [39]). Additionally, patients reported the frequent occurrence of other narcolepsy symptoms (Table 1 ). The mean values of all SF-36 domains at baseline showed impaired QoL (Table 1) and were not significantly different across treatment groups, except for the PCS $(p=0.040)$.

\section{Changes from Baseline}

Significant changes from baseline on the PCS were observed with all SXB doses $(p<0.05)$ but not with placebo (Fig. 1). The 9-g dose resulted in the greatest change (mean $\pm \mathrm{SD}$ ), $6.3 \pm 9.1$ points, which exceeded the MCID. This change was also significantly greater relative to the $1.5 \pm 6.2$ points with placebo $(p=0.005)$, and the difference demonstrated a moderate ES (0.616). In contrast, only the SXB 6-g dose resulted in a significant change from baseline on the MCS, and none of the changes with SXB was significant relative to placebo (Fig. 1).

Among the individual domains (Fig. 2), all SXB doses resulted in significant changes from baseline in Physical Functioning $(p<0.05)$ and Vitality $(p<0.001)$, with the 9-g dose observed to have greatest effect. The changes from baseline in Vitality exceeded the MCID for all SXB doses.

The 9-g dose also resulted in significant changes from baseline on Role-Physical $(p<0.05)$, Bodily Pain $(p<0.05), \quad \mathrm{GH}$ $(p<0.001)$, and Social Functioning $(p<0.05)$, with the changes of 6.4 and 6.8 exceeding the MCID for Role-Physical and Social Functioning, respectively (Fig. 2). A significant change from baseline was observed with placebo only for Role-Physical $(p<0.05)$.

In pairwise comparisons, Vitality was the only domain where all SXB doses showed significant differences relative to placebo (Fig. 2), and while the ES for the 4.5-g dose was small, at 0.394 , the ES for the 6.5 and $9-\mathrm{g}$ doses were moderate, at 0.518 and 0.728 , respectively. The SXB 4.5 and 6-g doses did not show significant differences compared to placebo for any of the other domains. However, the mean \pm SD change from baseline with the 9-g SXB dose was significantly greater than with placebo in the domains of Physical Functioning 
Table 1 Baseline demographic and clinical characteristics

\begin{tabular}{|c|c|c|c|c|c|}
\hline \multirow[t]{2}{*}{ Variable } & \multicolumn{4}{|l|}{ Value $^{\mathbf{a}}$} & \multirow[t]{2}{*}{$p$ value } \\
\hline & $\begin{array}{l}\text { Placebo } \\
(n=59)\end{array}$ & $\begin{array}{l}\text { SXB } 4.5 \mathrm{~g} \\
(n=64)\end{array}$ & $\begin{array}{l}\text { SXB } 6 \mathrm{~g} \\
(n=58)\end{array}$ & $\begin{array}{l}\text { SXB } 9 \text { g } \\
(n=47)\end{array}$ & \\
\hline Gender, $n(\%)$ & & & & & 0.582 \\
\hline Male & $17(28.8)$ & $21(32.8)$ & $22(37.9)$ & $19(40.4)$ & \\
\hline Female & $42(71.2)$ & $43(67.2)$ & $36(62.1)$ & $28(59.6)$ & \\
\hline Age, years, mean (SD) & $40.8(15.5)$ & $41.8(16.7)$ & $39.2(15.9)$ & $39.9(12.5)$ & 0.822 \\
\hline Race, $n(\%)$ & & & & & 0.306 \\
\hline White & $54(91.5)$ & $50(78.1)$ & $49(84.5)$ & $43(91.5)$ & \\
\hline Black & $3(5.1)$ & $11(17.2)$ & $7(12.1)$ & $4(8.5)$ & \\
\hline Other & $2(3.4)$ & $3(4.7)$ & $2(3.4)$ & 0 & \\
\hline ESS, mean (SD) & $17.3(3.7)$ & $18.0(4.0)$ & $18.2(3.0)$ & $17.8(4.0)$ & 0.462 \\
\hline \multicolumn{6}{|c|}{ Narcolepsy symptom episodes per week, mean (SD) } \\
\hline Cataplexy attacks & $18.9(14.8)$ & $38.0(121.0)$ & $26.5(27.4)$ & $25.6(29.3)$ & 0.408 \\
\hline Awakenings & $28.0(61.3)$ & $19.2(11.7)$ & $32.5(45.7)$ & $23.3(19.4)$ & 0.362 \\
\hline Hypnagogic hallucinations & $4.1(4.8)$ & $5.1(8.0)$ & $6.4(7.4)$ & $4.7(6.0)$ & 0.258 \\
\hline Sleep paralysis & $2.9(3.7)$ & $2.9(4.8)$ & $5.3(7.9)$ & $3.7(4.7)$ & 0.052 \\
\hline $\begin{array}{l}\text { Inadvertent naps/sleep } \\
\text { attacks }\end{array}$ & $14.6(9.1)$ & $18.6(15.7)$ & $21.0(11.9)$ & $18.5(17.7)$ & 0.077 \\
\hline \multicolumn{6}{|l|}{ SF-36 Score, mean (SD) } \\
\hline $\begin{array}{l}\text { Physical Component } \\
\text { Summary }\end{array}$ & $42.2(8.3)^{b}$ & $45.1(8.5)$ & $46.3(9.0)$ & $42.7(8.9)$ & 0.040 \\
\hline $\begin{array}{l}\text { Mental Component } \\
\text { Summary }\end{array}$ & $40.5(10.6)^{b}$ & $42.7(12.0)$ & $38.5(10.2)$ & $40.6(11.3)$ & 0.236 \\
\hline Physical Functioning & $44.5(9.9)^{b}$ & $45.9(10.8)$ & $46.1(8.0)$ & $43.6(10.9)$ & 0.509 \\
\hline Role-Physical & $34.7(9.4)^{b}$ & $38.0(11.4)$ & $37.8(11.1)$ & $35.3(11.3)$ & 0.230 \\
\hline Bodily Pain & $47.8(10.6)^{b}$ & $50.6(10.3)$ & $50.9(10.0)$ & $49.3(10.1)$ & 0.348 \\
\hline General Health & $43.0(9.1)^{b}$ & $47.5(10.0)$ & $45.1(11.4)$ & $45.0(9.7)$ & 0.124 \\
\hline Vitality & $37.4(8.9)^{\mathrm{b}}$ & $38.9(10.8)$ & $37.7(8.9)$ & $36.6(10.6)$ & 0.673 \\
\hline Social Functioning & $34.3(13.2)^{b}$ & $38.1(12.8)$ & $37.1(11.7)$ & $33.6(13.9)$ & 0.194 \\
\hline Role-Emotional & $40.8(13.4)^{b}$ & $45.8(12.3)$ & $39.9(13.1)$ & $41.7(13.9)$ & 0.065 \\
\hline Mental Health & $46.2(9.2)^{b}$ & $45.7(11.6)$ & $43.5(10.2)$ & $46.6(10.5)$ & 0.410 \\
\hline
\end{tabular}

ESS Epworth Sleepiness Scale, $S D$ standard deviation, $S X B$ sodium oxybate

${ }^{a}$ Values are for the intent-to-treat population defined as patients who received at least one dose of study medication and had baseline and post-baseline efficacy measurements

b $n=58$ 


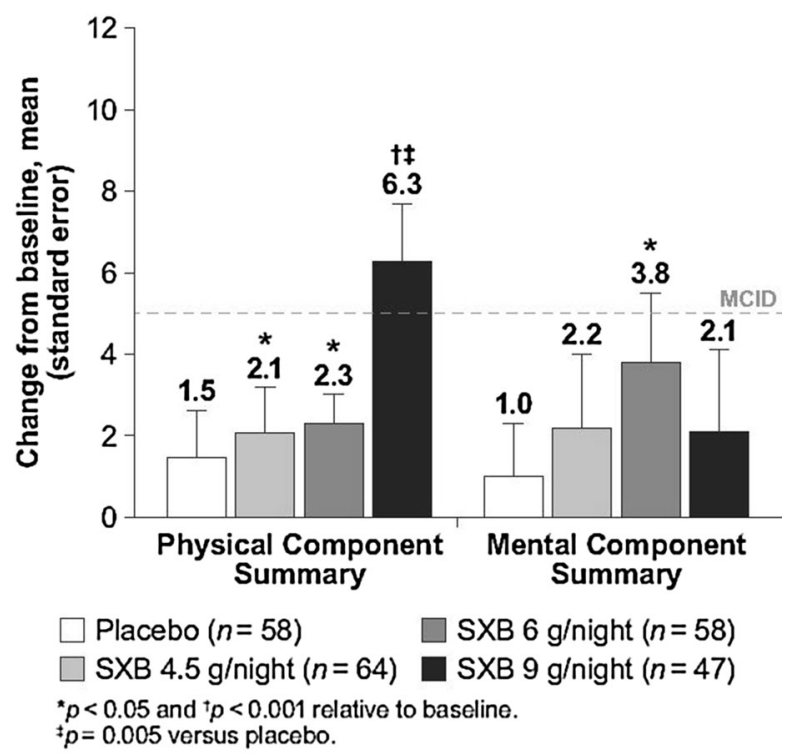

Fig. 1 Change from baseline at 8 weeks in SF-36 component summary scores. Data are for the intent-to-treat population using last observation carried forward; broken horizontal line represents the minimum clinically important difference (MCID)
$(4.4 \pm 9.2 \quad$ vs. $\quad 1.0 \pm 8.0 ; \quad p=0.016), \quad \mathrm{GH}$ $(3.1 \pm 7.0$ vs. $0.4 \pm 6.8 ; p=0.036)$, and Social Functioning $(6.8 \pm 16.8$ vs. $1.1 \pm 9.6 ; p=0.033$; Fig. 2); these differences resulted in small ES of $0.394,0.395$, and 0.417 , respectively.

\section{DISCUSSION}

\section{Dose-Dependent HRQoL Response}

This study found that SXB treatment in patients with narcolepsy was associated with improved HRQoL in a dose-dependent manner, and that the 9-g dose provided the greatest benefits. Consistent with other studies [18-20, 22, 24], these patients were characterized by impaired HRQoL, as shown by baseline values across all SF-36 domains that were lower than normative SF-36 values for the US population [35]. SF-36

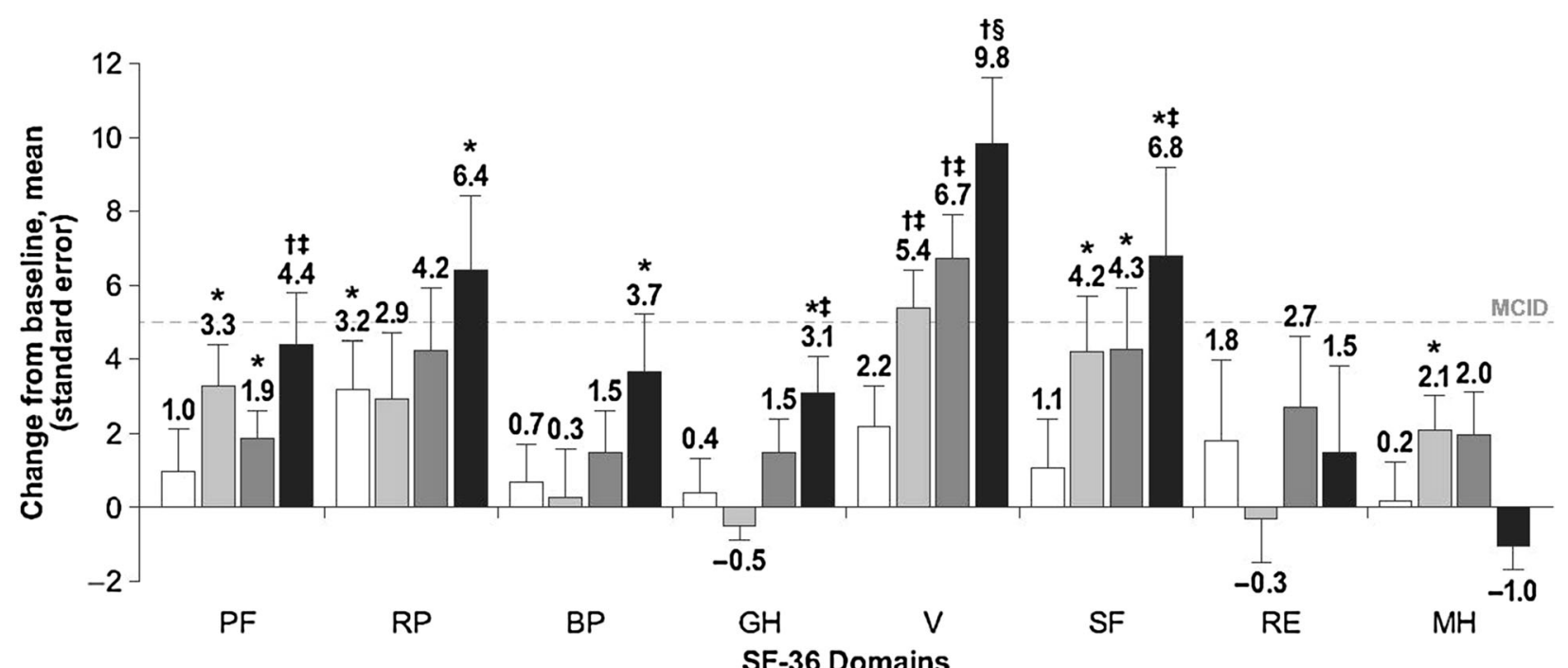

\footnotetext{
Placebo ( $n=58) \quad \square$ SXB 4.5 g/night $(n=64)$ ${ }^{*} p<0.05$ and ${ }^{t} p<0.001$ relative to baseline. $t^{t} p<0.05$ and $s p<0.001$ versus placebo.
}

Fig. 2 Change from baseline at 8 weeks in SF-36 domain scores. Data are for the intent-to-treat population using last observation carried forward; broken horizontal line represents the minimum clinically important difference (MCID). PF Physical Functioning, $R P$ Role-Physical, BP Bodily Pain, GH General Health, $V$ Vitality, $S F$ Social Functioning, $R E$ Role-Emotional, $M H$ Mental Health 
domain scores were also generally lower than those reported in most other narcolepsy studies that used this measure [14, 18-24], indicating greater impairment of HRQoL at baseline. In these patients, the frequency of narcolepsy symptoms and the high ESS scores are consistent with moderate-to-severe narcolepsy.

Significant improvements with SXB relative to placebo were observed on the PCS and in four of the eight SF-36 subscales, including Physical Functioning, GH, Vitality, and Social Functioning. Notably, the greatest changes from baseline with SXB were consistently observed in the Vitality domain across all doses, also exceeding the MCID by a five-point change. This domain was also the only one that showed statistically significant differences compared to placebo for all SXB doses. Vitality, which is interpreted as a measure of energy and fatigue, is the subscale that is often reported to have the lowest value among the SF-36 domains in patients with narcolepsy as well as in the general population [18, 22, 24]. Although fatigue has not been considered a core symptom of narcolepsy, it is frequently reported by patients with narcolepsy $[40,41]$.

The significant changes from baseline in the SF-36 Role-Physical and Social Functioning domains, which also exceeded the MCID and were significantly greater relative to placebo, are consistent with previously reported improvements in functional outcomes with SXB as measured by the FOSQ [32]. The SF-36 Role-Physical would be analogous to the General Productivity domain on the FOSQ, and SF-36 Social Functioning would be analogous to the FOSQ Social Outcomes; both FOSQ functional outcomes showed dose-dependent improvements for the 6-g and 9-g SXB doses and large ES relative to placebo [32].

There were some improvements in MCS with SXB, but these were not statistically significantly different from placebo. This lack of an effect may suggest that the MCS is more a measure of mental health (i.e., anxiety/ depression) than cognitive function [41, 42]. It should be noted that a previous analysis from this study that used the FOSQ did report that 6-g and 9-g SXB doses were associated with significantly greater improvements relative to placebo in the Vigilance domain [32]. This domain assesses the cognitive functions of attention and concentration.

\section{Limitations}

Limitations of this study include the 8-week study duration. This observational period may not be long enough to capture changes in patient-reported QoL outcomes that may be associated with narcolepsy treatment [24]. Clinically meaningful changes in EDS and cataplexy with SXB may require 2 months or more, and a longer period is required to achieve maximum response [43]. Another limitation is that the SF-36 is a disease-independent assessment, and while it may be appropriate for an overall understanding of HRQoL in patients with narcolepsy relative to other populations, it may not be fully responsive to changes in domains associated with narcolepsy treatment effects. Consequently, a disease-specific measure is needed that could more sensitively capture changes in outcomes that impact HRQoL in patients with this disorder. Nevertheless, the results of the current study showed improvements in several SF-36 subscales at the 9-g/day dose of SXB. Finally, the use of the generally accepted MCID of five points to indicate clinically meaningful improvements could be criticized, since the MCID is likely to vary across conditions. However, in the absence of disease-specific values, this threshold provides a relative 
measure for interpreting the observed improvements.

\section{CONCLUSIONS}

SXB appears to improve QoL measures in a dose-dependent manner, with the largest impact at the 9-g/night dose, which had a significant effect on the Vitality, GH, and Physical and Social Functioning domains of the SF-36. Studies of longer duration may be needed to more fully evaluate the effects of SXB on HRQoL in patients with narcolepsy, and the results reported here also highlight the need for a narcolepsy-specific measure of HRQoL.

\section{ACKNOWLEDGMENTS}

Funding support for this research was provided by Orphan Medical, Inc., and Jazz Pharmaceuticals. Sponsorship for article processing charges was provided by Jazz Pharmaceuticals. All named authors meet the International Committee of Medical Journal Editors (ICMJE) criteria for authorship for this manuscript, take responsibility for the integrity of the work as a whole, and have given final approval for the version to be published. Under the direction of the authors, E. Jay Bienen, Ph.D., of The Curry Rockefeller Group, LLC (CRG), provided editorial assistance for this publication. Editorial assistance in formatting, proofreading, copy editing, and fact checking was also provided by CRG. Jazz Pharmaceuticals provided funding to CRG for all editorial support of this manuscript. Each author has certified that they have made substantial contributions to all aspects of this manuscript, including conception and planning, analysis and interpretation of data, and drafting and critical revision. All authors have read and approved the submitted version. As corresponding author, Richard Bogan will act as the overall guarantor.

Disclosures. R. Bogan is a shareholder and an employee of SleepMed, Inc; has received consultant fees from Jazz Pharmaceuticals, UCB, and XenoPort; has received industry-funded research support from Jazz Pharmaceuticals, Philips, ApniCure, and Fisher \& Paykel; and has been a speakers bureau member for Teva, Jazz Pharmaceuticals, UCB, Vanda, Merck, and XenoPort. T. Swick is an employee of Neurology and Sleep Medicine Consultants; has received consultancy fees and/ or honoraria from Jazz Pharmaceuticals, Vanda Pharmaceuticals, XenoPort Pharmaceuticals, UCB Pharma, Merck, and Aerial BioPharma; has received grant/research funding from Jazz Pharmaceuticals, Aerial BioPharma, GSK Pharmaceuticals, Otsuka Pharmaceuticals, Teva Pharmaceuticals, Vanda Pharmaceuticals, UCB Pharma, XenoPort Pharmaceuticals, and Merck; and is on the speakers bureau for Jazz Pharmaceuticals, XenoPort Pharmaceuticals, Teva Pharmaceuticals, Merck, and UCB Pharma. M. Mamelak has received consultancy fees from Jazz Pharmaceuticals. R. Kovacevic-Ristanovic has received honoraria as a speaker for Jazz Pharmaceuticals. C. Lai was an employee of Jazz Pharmaceuticals while the study was being conducted and, in the course of this employment, received stock options exercisable for, and other stock awards of, ordinary shares of Jazz Pharmaceuticals plc. K.F. Villa is an employee of Jazz Pharmaceuticals, who in the course of this employment has received stock options exercisable for, and other stock awards of, ordinary shares of Jazz Pharmaceuticals plc. J. Black is a part-time 
employee of Jazz Pharmaceuticals, and holds stock in Jazz Pharmaceuticals plc. J. Montplaisir has received consultancy fees from Jazz Pharmaceuticals, Merck, UCB, and Valeant Pharmaceuticals; and has received research funding from GSK and Merck.

Compliance with Ethical Standards. All procedures followed were in accordance with the ethical standards of the responsible committee on human experimentation (institutional and national) and with the Helsinki Declaration of 1964, as revised in 2013. Informed consent was obtained from all patients for inclusion in the study.

Open Access. This article is distributed under the terms of the Creative Commons AttributionNonCommercial 4.0 International License (http://creativecommons.org/licenses/by-nc/4. $0 /$ ), which permits any noncommercial use, distribution, and reproduction in any medium, provided you give appropriate credit to the original author(s) and the source, provide a link to the Creative Commons license, and indicate if changes were made.

\section{REFERENCES}

1. Nishino S, Mignot E. Narcolepsy and cataplexy. Handb Clin Neurol. 2011;99:783-814.

2. Roth T, Dauvilliers Y, Mignot E, Montplaisir J, Paul J, Swick T, et al. Disrupted nighttime sleep in narcolepsy. J Clin Sleep Med. 2013;9(9):955-65.

3. Dauvilliers Y, Montplaisir J, Molinari N, Carlander $\mathrm{B}$, Ondze $\mathrm{B}$, Besset $\mathrm{A}$, et al. Age at onset of narcolepsy in two large populations of patients in France and Quebec. Neurology. 2001;57(11):2029-33.

4. Okun ML, Lin L, Pelin Z, Hong S, Mignot E. Clinical aspects of narcolepsy-cataplexy across ethnic groups. Sleep. 2002;25(1):27-35.
5. Thorpy MJ, Krieger AC. Delayed diagnosis of narcolepsy: characterization and impact. Sleep Med. 2014;15(5):502-7.

6. Kryger $\mathrm{MH}$, Walid R, Manfreda J. Diagnoses received by narcolepsy patients in the year prior to diagnosis by a sleep specialist. Sleep. 2002;25(1):36-41.

7. Kauta SR, Marcus CL. Cases of pediatric narcolepsy after misdiagnoses. Pediatr Neurol. 2012;47(5):362-5.

8. Dodel R, Peter H, Walbert T, Spottke A, Noelker C, Berger $\mathrm{K}$, et al. The socioeconomic impact of narcolepsy. Sleep. 2004;27(6):1123-8.

9. Jennum P, Knudsen S, Kjellberg J. The economic consequences of narcolepsy. J Clin Sleep Med. 2009;5(3):240-5.

10. Jennum $\mathrm{P}$, Ibsen $\mathrm{R}$, Petersen ER, Knudsen $\mathrm{S}$, Kjellberg J. Health, social, and economic consequences of narcolepsy: a controlled national study evaluating the societal effect on patients and their partners. Sleep Med. 2012;13(8):1086-93.

11. Ohayon MM. Narcolepsy is complicated by high medical and psychiatric comorbidities: a comparison with the general population. Sleep Med. 2013;14(6):488-92.

12. Ohayon MM, Black J, Lai C, Eller M, Guinta D, Chattacharyya A. Increased mortality in narcolepsy. Sleep. 2014;37(3):439-44.

13. Jennum $\mathrm{P}$, Ibsen $\mathrm{R}$, Knudsen $\mathrm{S}$, Kjellberg J. Comorbidity and mortality of narcolepsy: a controlled retro- and prospective national study. Sleep. 2013;36(6):835-40.

14. Daniels E, King MA, Smith IE, Shneerson JM. Health-related quality of life in narcolepsy. J Sleep Res. 2001;10(1):75-81.

15. Vignatelli L, D'Alessandro R, Mosconi P, Ferini-Strambi L, Guidolin L, De Vincentiis A, et al. Health-related quality of life in Italian patients with narcolepsy: the SF-36 health survey. Sleep Med. 2004;5(5):467-75.

16. Vignatelli L, Plazzi G, Peschechera F, Delaj L, D'Alessandro R. A 5-year prospective cohort study on health-related quality of life in patients with narcolepsy. Sleep Med. 2011;12(1):19-23.

17. Inocente $\mathrm{CO}$, Gustin $\mathrm{MP}$, Lavault $\mathrm{S}$, Guignard-Perret A, Raoux A, Christol N, et al. Quality of life in children with narcolepsy. CNS Neurosci Ther. 2014;20(8):763-71. 
18. Dodel R, Peter H, Spottke A, Noelker C, Althaus A, Siebert $U$, et al. Health-related quality of life in patients with narcolepsy. Sleep Med. 2007;8(7-8):733-41.

19. David A, Constantino F, dos Santos JM, Paiva T. Health-related quality of life in Portuguese patients with narcolepsy. Sleep Med. 2012;13(3):273-7.

20. Ervik S, Abdelnoor M, Heier MS, Ramberg M, Strand G. Health-related quality of life in narcolepsy. Acta Neurol Scand. 2006;114(3):198-204.

21. Teixeira VG, Faccenda JF, Douglas NJ. Functional status in patients with narcolepsy. Sleep Med. 2004;5(5):477-83.

22. Campbell AJ, Signal TL, O'Keeffe KM, Bakker JP. Narcolepsy in New Zealand: pathway to diagnosis and effect on quality of life. $\mathrm{N} Z$ Med J. 2011;124(1336):51-61.

23. Ozaki A, Inoue $Y$, Nakajima $T$, Hayashida $\mathrm{K}$, Honda M, Komada Y, et al. Health-related quality of life among drug-naive patients with narcolepsy with cataplexy, narcolepsy without cataplexy, and idiopathic hypersomnia without long sleep time. J Clin Sleep Med. 2008;4(6):572-8.

24. Beusterien KM, Rogers AE, Walsleben JA, Emsellem HA, Reblando JA, Wang L, et al. Health-related quality of life effects of modafinil for treatment of narcolepsy. Sleep. 1999;22(6):757-65.

25. Billiard M, Bassetti C, Dauvilliers Y, Dolenc-Groselj L, Lammers GJ, Mayer G, et al. EFNS guidelines on management of narcolepsy. Eur J Neurol. 2006;13(10):1035-48.

26. Morgenthaler TI, Kapur VK, Brown T, Swick TJ, Alessi C, Aurora RN, et al. Practice parameters for the treatment of narcolepsy and other hypersomnias of central origin. Sleep. 2007;30(12):1705-11.

27. Xyrem $^{\circledR}$ (sodium oxybate) oral solution [prescribing information]. Jazz Pharmaceuticals, Inc., Palo Alto, CA; April 2014.

28. The US Xyrem Multi-Center Study Group. A randomized, double blind, placebo-controlled multicenter trial comparing the effects of three doses of orally administered sodium oxybate with placebo for the treatment of narcolepsy. Sleep. 2002;25(1):42-9.

29. Xyrem International Study Group. A double-blind, placebo-controlled study demonstrates sodium oxybate is effective for the treatment of excessive daytime sleepiness in narcolepsy. J Clin Sleep Med. 2005;1(4):391-7.
30. Xyrem International Study Group. Further evidence supporting the use of sodium oxybate for the treatment of cataplexy: a double-blind, placebo-controlled study in 228 patients. Sleep Med. 2005;6(5):415-21.

31. Weaver TE, Laizner AM, Evans LK, Maislin G, Chugh DK, Lyon K, et al. An instrument to measure functional status outcomes for disorders of excessive sleepiness. Sleep. 1997;20(10):835-43.

32. Weaver TE, Cuellar N. A randomized trial evaluating the effectiveness of sodium oxybate therapy on quality of life in narcolepsy. Sleep. 2006;29(9):1189-94.

33. Ware JE Jr, Sherbourne CD. The MOS 36-item short-form health survey (SF-36). I. Conceptual framework and item selection. Med Care. 1992;30(6):473-83.

34. McHorney CA, Ware JE Jr, Raczek AE. The MOS 36-Item Short-Form Health Survey (SF-36): II. Psychometric and clinical tests of validity in measuring physical and mental health constructs. Med Care. 1993;31(3):247-63.

35. Ware JE, Snow KK, Kosinski M, Gandek B. SF-36 Health Survey Manual and Interpretation Guide. Boston: The Health Institute, New England Medical Center; 1993.

36. Hays RD, Morales LS. The RAND-36 measure of health-related quality of life. Ann Med. 2001;33(5):350-7.

37. Ware JE Jr, Kosinski M. Physical and mental health summary scales: a manual for users of version 1 . Second ed. Lincoln: Quality Metric Inc; 2003.

38. Cohen J. Statistical power analysis for the behavioral sciences. 2nd ed. Hillsdale: Lawrence Erlbaum Associates; 1988.

39. Johns MW. A new method for measuring daytime sleepiness: the Epworth Sleepiness Scale. Sleep. 1991;14(6):540-5.

40. Droogleever Fortuyn HA, Fronczek R, Smitshoek M, Overeem S, Lappenschaar M, Kalkman J, et al. Severe fatigue in narcolepsy with cataplexy. J Sleep Res. 2012;21(2):163-9.

41. U.S. Food and Drug Administration. The Voice of the Patient: Narcolepsy. June 2014. Available from: http://www.fda.gov/downloads/ForIndustry/User Fees/PrescriptionDrugUserFee/UCM402907.pdf.

42. Bayard S, Croisier Langenier M, Cochen De Cock V, Scholz S, Dauvilliers Y. Executive control of attention in narcolepsy. PLoS One. 2012;7(4):e33525. 
43. Bogan RK, Roth T, Schwartz J, Miloslavsky M. Time to response with sodium oxybate for the treatment of excessive daytime sleepiness (EDS) and cataplexy in patients with narcolepsy. J Clin Sleep Med. 2015;11(4):427-32. 